\title{
A Ética do Discurso e o Modelo dos Consensos Democráticos: Uma Réplica a J. Eisenberg*
}

\author{
Christina W. Andrews
}

P ode-se dizer que Jürgen Habermas tem muito em comum com Max Weber. Não me refiro apenas à conhecida influência de
Weber sobre a teoria social de Habermas, mas principalmente a um destino aparentemente comum aos dois teóricos sociais alemães: alguns de seus conceitos fundamentais não escaparam a interpretações equivocadas. Não são poucos os manuais destinados a estudantes de administração que apresentam o conceito weberiano de "tipo ideal" de burocracia como se este significasse uma "recomendação" desse tipo de organização (Leivesley et alii, 1994).

Tudo indica que a obra de Habermas já sofre do mesmo mal que se abateu sobre a de Weber. Objeto de inúmeras análises críticas, e tendo servido de referência para estudos em diversos campos do conheci-

\footnotetext{
* Agradeço a Celina Souza, Encarnación Moya Recio, Gabriel Cohn, João Carlos Haddad, Júlio César Casarin Barroso Silva e Sergio Daniel Morresi pelos valiosos comentários a uma versão anterior deste texto e que muito contribuíram para o seu aperfeiçoamento, a Marcelo Assis pela assessoria na formulação do "experimento de pensamento" e aos dois pareceristas anônimos de Dados que avaliaram o presente artigo. Todos os possíveis erros e eventuais omissões são de minha exclusiva responsabilidade. Agradeço também à Fundação de Amparo à Pesquisa do Estado de São Paulo FAPESP, cujo apoio financeiro viabilizou os estudos pertinentes ao tema aqui tratado.
}

DADOS - Revista de Ciências Sociais, Rio de Janeiro, Vol. 45, nㄴ 4, 2002, pp. 577 a 597. 
mento - da sociologia à administração pública, passando pela teoria política e filosofia moral -, a crescente influência da abordagem de Habermas nas ciências sociais também acarretou problemas: seus conceitos têm sido muitas vezes mal compreendidos, o que acaba prejudicando a própria recepção crítica de seus argumentos. A culpa por esses mal-entendidos recai, pelo menos em parte, sobre o próprio Habermas. Seus textos adotam um estilo notoriamente abstruso, o que acaba dificultando o acesso a seus argumentos, característica que, como notou Martin Jay (1984), é compartilhada por praticamente todos os teóricos identificados com o marxismo ocidental. McCarthy (1981) sugere que os erros de interpretação seriam conseqüência do fato de os escritos de Habermas só poderem ser compreendidos em seu conjunto. A demora na tradução para o inglês de seus livros fundamentais - em especial, The Theory of Communicative Action (1984; 1987), seu magnum opus - teria contribuído para a difusão de alguns equívocos, uma vez que os primeiros comentadores do pensamento habermasiano fora da Alemanha se basearam em uns poucos artigos disponíveis em inglês. Em que pesem essas considerações, pode-se dizer que a responsabilidade pelos mal-entendidos é questão secundária, e o que importa é empreender um esforço para desfazê-los. Só assim, a contribuição teórica de Habermas poderá ser recolocada na perspectiva adequada para o debate crítico.

Meu propósito aqui é esclarecer alguns conceitos utilizados por Habermas e adotados no artigo "Justificação, Aplicação e Consenso: Notas sobre Democracia e Deliberação", de José Eisenberg (2001)1. Argumentarei que este, ao apresentar um modelo de interpretação de arranjos políticos nas sociedades contemporâneas - que chamarei de "modelo dos consensos democráticos" -, atribui sentidos aos conceitos contidos na "ética do discurso" (Diskursethik) que diferem daqueles utilizados por Habermas. Por isso, a teoria habermasiana acaba não servindo às intenções pretendidas por Eisenberg. Procurarei, também, apontar alguns problemas de consistência teórica do modelo dos consensos democráticos que, se não esclarecidos, comprometem sua plausibilidade. Esses dois aspectos estão interligados e, por isso, não serão discutidos separadamente.

Eisenberg sustenta que, a partir do processo de formação de consensos na esfera política, são obtidos quatro mecanismos de arbitragem que correspondem, por sua vez, a quatro tipos de consensos democráticos: comunitarista, liberal, autoritativo e republicano. O autor tam- 
bém afirma que há uma dinâmica de transição entre esses consensos, que ele denomina de "círculo virtuoso da democracia". Se a passagem de um tipo de consenso para outro não for possível, emergirão patologias sociopolíticas: fundamentalismo, apatia, separatismo e violência. Para desenvolver seu argumento, ele parte do modelo de democracia deliberativa de Habermas, mas deixa claro que vê deficiências na abordagem habermasiana e se propõe a apresentar uma proposta capaz de superá-las.

Eisenberg entende a democracia como um conjunto de regras de formação da vontade política que fundamentam sua legitimidade em processos deliberativos. Segundo ele, um consenso é "democrático se ele resulta de mecanismos de arbitragem em que atores em posição de igualdade formal consentem à validez das instituições resultantes." (:198) Essa formulação não difere da de democracia deliberativa de Habermas (1998a), fundamentada no argumento de que a validação discursiva de regras de deliberação democrática - ou seja, mecanismos de arbitragem, segundo a terminologia adotada por Eisenberg - é o que confere legitimidade às decisões tomadas por meio dessas. $\mathrm{O}$ autor aceita o argumento de Habermas no que se refere aos critérios para se atribuir legitimidade aos procedimentos de deliberação. No entanto, ao enfatizar o aspecto da aceitação ou rejeição dos resultados da deliberação democrática, Eisenberg abre caminho para um mal-entendido conceitual que é, no passo seguinte, incorporado ao modelo dos consensos democráticos. Ele afirma que

\footnotetext{
"[...] os resultados do processo deliberativo não precisam ser aceitáveis para todos os participantes; basta que as regras daquele processo o sejam e, como especificado pelo "princípio do discurso" (chamado de princípio D) da ética de Habermas, que todos aqueles potencialmente afetados pela norma cheguem a um acordo quanto à sua validez." (:198, ênfases minhas)
}

Ou seja, Eisenberg interpreta o conceito de "aplicação" da ética do discurso de Habermas como sendo a aceitação (ou rejeição) de normas que resultam de um processo de deliberação legítimo. Entretanto, como Habermas argumentou em Justification and Application (1993), "aplicação" é uma forma de discurso e não uma constatação empírica quanto à aceitação ou rejeição de normas de interação social. Segundo este argumento, o discurso de justificação tem como meta validar uma norma moral, enquanto o discurso de aplicação tem por objeti- 
vo deliberar se a norma moral se aplica a uma determinada situação específica. Como observou Rehg (1997), o processo do discurso de aplicação envolve principalmente a hierarquização de normas morais em conflito. Atores sociais podem decidir que determinada norma não se aplica ao caso em questão e que outra deve ser considerada mais importante, dependendo do contexto em que se encontrem. Temos de ter em mente que Habermas considera que normas morais são aquelas com validade universal, ou seja, são as que, em princípio, devem ser consideradas justas e, portanto, válidas para todos os atores pertinentes ${ }^{2}$. Os contextos específicos, porém, determinam que normas morais terão precedência sobre outras. Dessa forma, por meio do discurso de aplicação, uma norma moral é qualificada por outras normas que são trazidas à consideração dos participantes do discurso prático pelas circunstâncias do contexto. Rehg mostra que esse tipo de procedimento está implícito em frases que expressam desculpas, como, por exemplo: "Eu teria chegado no horário combinado, mas me atrasei porque minha filha ficou doente" (idem:190). Ele também argumenta que a qualificação obtida nesse tipo de discurso prático é candidata a se tornar uma norma universal. Por exemplo, a norma "não se deve mentir" qualificada pela norma "deve-se proteger um inocente" resulta na norma universal "deve-se proteger um inocente, mesmo que isso signifique mentir" (idem:196) ${ }^{3}$. Em suma, uma norma pode ser considerada justa, mas se a mesma se aplica à determinada situação concreta depende de uma avaliação dos participantes, o que constitui um passo adicional do processo discursivo. Mas o que Habermas considera como sendo um discurso?

O discurso habermasiano corresponde ao processo de avaliação crítica de reivindicações de validade apresentadas por atores sociais que visam ao entendimento mútuo por meio do consenso. O pressuposto do discurso é a situação ideal de fala, ou seja, um contexto livre de dominação tal que permita aos participantes chegar ao entendimento mútuo. Temos aqui um aspecto da teoria habermasiana que é freqüentemente mal compreendido: a situação ideal de fala não é requisito prévio para a prática da racionalidade comunicativa e sim um pressuposto assumido pelos participantes de um discurso autêntico ${ }^{4}$. É importante observar que a condição de pressuposto também se aplica à idéia de consenso, como observou Habermas:

"Somente nos discursos teórico, prático e explicativo, os participantes têm que partir do pressuposto (freqüentemente contrafactual) de que 


\section{A Ética do Discurso e o Modelo dos Consensos Democráticos...}

as condições para uma situação ideal de discurso são atendidas em um grau suficientemente satisfatório. Eu chamarei de 'discurso' somente a situação na qual o sentido da reivindicação de validade problemática força conceitualmente os participantes a supor que um acordo poderia, em princípio, ser alcançado, notando-se que a frase 'em princípio' expressa a condição ideal: se a argumentação pudesse ser conduzida de maneira suficientemente aberta e se pudesse durar o tempo suficiente." (1984:40, ênfases minhas)

Habermas (idem) também observa que, na prática comunicativa do dia-a-dia, o entendimento mútuo é frágil, tentativo e passível de revisão permanente. $O$ consenso refere-se, antes de tudo, a uma expectativa racional dos participantes, ainda que seja também uma possibilidade empírica. Entretanto, a facticidade empírica não é necessária para o uso do conceito habermasiano de consenso, pois quando atores sociais estão engajados em um processo de entendimento mútuo, o consenso como pressuposto está presente. Isto é fundamental para toda a obra de Habermas, pois para ele a linguagem já pressupõe um "consenso universal e irrestrito" (Habermas, 1971:314).

Como vimos, Habermas nos diz que o processo de validação de normas morais inclui dois passos: o discurso de justificação e o discurso de aplicação. Para que uma norma tenha validade universal, é preciso que ela atenda ao "princípio de universalização" (U), definido como a situação em que "todos os afetados podem aceitar as conseqüências e efeitos secundários que a aceitação geral [da norma] é esperada de causar na satisfação dos interesses de todos (e essas conseqüências são preferíveis àquelas possíveis alternativas para a regulação)" (Habermas, 1990:65). Assim como a situação ideal de discurso, o princípio (U) também é considerado um pressuposto racional que os participantes do discurso prático assumem ao deliberarem sobre normas que se pretendem justas. Em outras palavras, participantes de um discurso prático pressupõem que os critérios estipulados pelo princípio (U) podem ser contemplados quando buscam obter um consenso sobre normas morais. Portanto, o princípio (U) expressa os critérios que devem ser atendidos para que a norma em questão esteja de acordo com o princípio moral geral - o princípio (D), mencionado por Eisenberg. O discurso de aplicação, por sua vez, busca atender ao "princípio de propriedade" ${ }^{\text {, }}$ que consiste na avaliação da aplicabilidade de determinada norma moral a um contexto específico por meio de um processo de hierarquização de normas. Os papéis desempe- 
nhados pelo princípio de universalização e pelo princípio de propriedade são complementares, mas distintos. Deve-se ter em mente que o discurso de aplicação só tem lugar depois que um consenso por meio do discurso de justificação é alcançado.

Portanto, na ética do discurso de Habermas, "aplicação" é uma modalidade de discurso prático. Para ele, a questão da aceitação ou rejeição de normas relaciona-se com o problema da legitimidade (Habermas, 1998a). É preciso notar, porém, que Habermas não considera que normas são legítimas somente pelo fato de serem aceitas pelos destinatários. Elas são legítimas quando atendem ao critério de legislação legítima, ou seja, ao "princípio de democracia". Este estipula que apenas aqueles estatutos que podem contar com o consentimento [Zustimmung] de todos os cidadãos, obtido por meio de regras discursivas de legislação que tenham sido, por sua vez, legalizadas, podem ser considerados legítimos (idem). A legislação legítima refere-se a uma comunidade política formalmente estabelecida, na qual a expectativa é que as normas legitimadas pelo princípio de democracia sejam aceitas pelos destinatários quando puderem ser justificadas. Porém, a aceitação empírica de normas não é a fonte da legitimidade.

"A legitimidade de um estatuto é independente de sua implementação de facto. Ao mesmo tempo, porém, a validade de facto ou adesão [compliance] varia de acordo com a crença dos destinatários na legitimidade [do estatuto], e essa crença é, por sua vez, baseada na suposição de que a norma poderia ser justificada. Quanto mais frágil for a legitimidade de uma ordem legal, ou ao menos considerada como tal, tanto mais outros fatores, tais como intimidação, a força das circunstâncias, costume e puro hábito, devem assumir posição para garanti-la." (idem:30)

Em outras palavras, se há adesão espontânea a uma lei, pode-se supor que os destinatários desta a reconheçam como legítima e sejam capazes de justificá-la racionalmente. Se, por outro lado, há baixa adesão (ou seja, pouca "aceitação") a uma lei, é porque seus destinatários não a têm como suficientemente legítima e não encontram argumentos para justificá-la. Em suma, em uma comunidade política qualquer, para que normas formais (leis) sejam consideradas legítimas, elas precisam atender aos seguintes critérios: (a) devem ser submetidas a um processo deliberativo; (b) as regras do processo deliberativo devem ter sido validadas discursivamente; (c) as regras de deliberação 
foram institucionalizadas na forma de lei. Atendidos estes critérios, a expectativa é que a adesão a essas normas seja espontânea - ou quase. Deve-se ter em mente que normas formais exigem sanções. Atores sociais podem escolher agir estrategicamente, ignorando as normas legitimadas pela comunidade política. Portanto, o bem-estar geral só pode ser garantido se atores auto-interessados forem dissuadidos de agir contra o interesse geral por meio da aplicação de sanções. O interesse geral, por sua vez, só pode ser estabelecido mediante procedimentos de deliberação democrática. É essa dinâmica, entre a legitimidade discursiva das leis e a necessidade de aplicação de sanções, que Habermas (idem) identificou como sendo a tensão entre a validade e facticidade da lei. Esta deve atender ao princípio de democracia, de outro modo não poderia ser considerada legítima; mas ela também precisa aplicar sanções para forçar atores que agem estrategicamente a adaptar seus comportamentos de forma a preservar o interesse geral. Portanto, em sociedades complexas, tanto a legitimação discursiva como a aplicação de sanções são elementos necessários ao processo democrático.

Para Habermas, as regras de deliberação também incluem processos deliberativos que não visam necessariamente ao consenso: trata-se da barganha justa. A diferença entre o consenso e a barganha justa reside nas razões sustentadas pelos grupos de interesse envolvidos. "Enquanto consensos racionalmente motivados (Einverständnis) se baseiam em razões que convencem todos os grupos da mesma maneira, um compromisso pode ser aceito por grupos diferentes, cada um segundo suas razões próprias e diferentes" (idem:166). Eisenberg, porém, parece achar que as barganhas, por envolverem interesses não generalizáveis, não seriam procedimentos democráticos. "Contratos, barganhas e outros mecanismos em que se articulam interesses de atores em posições de igualdade formal [argumenta Eisenberg] não necessariamente constituem mecanismos democráticos" (:199). No entanto, Eisenberg sustenta que

"Do ponto de vista da política nas sociedades contemporâneas, a redução da complexidade sistêmica traduz-se em democracia, isto é, em um conjunto de mecanismos de arbitragem que visa resolver o problema da produção de consentimentos legítimos em contextos nos quais o consenso efetivo e a persuasão mútua são horizontes impossíveis." $(: 198)$ 
Apesar da constatação de que o consenso muitas vezes é inviável, na avaliação de Eisenberg as barganhas permanecem em um limbo, pois não são consideradas mecanismos de arbitragem e, portanto, não seriam procedimentos democráticos legítimos. Essa questão parece estar relacionada com o conceito de consenso. Eisenberg, embora siga o modelo de democracia deliberativa de Habermas como ponto de partida, não adota a idéia de "consenso" como um pressuposto de discursos práticos: ele constrói o seu modelo a partir da idéia de consensos empíricos obtidos por meio de deliberações nas "posições iniciais", um elemento heurístico que toma emprestado das teorias políticas contratualistas. Com isso, os conceitos habermasianos baseados em pressupostos discursivos são introduzidos em um argumento teórico que depende da postulação de consensos empíricos, uma estratégia que se revelará problemática para o modelo dos consensos democráticos. Para abordar esta questão, vamos retomar um aspecto mencionado acima: o uso que Eisenberg faz do conceito habermasiano de "aplicação".

Podemos sintetizar o mal-entendido conceitual presente no argumento de Eisenberg nos seguintes termos: o termo "aplicação" é adotado como sinônimo de adesão de facto a normas - ou seja, como "aceitação" - e não como uma modalidade de discurso, como faz Habermas. Dessa maneira, ele introduz uma mudança fundamental no conceito habermasiano original. Porém, não faz uma preparação para esse "salto" conceitual, mas apenas aplica o novo conceito à idéia das posições iniciais, apresentando o seguinte argumento:

"Temos, então, dois planos em que esses consensos normativos são formados via deliberação - o plano da justificação e o da aplicação de normas -, e a convergência em um ou dois destes planos gera quatro cenários que podem ser analiticamente definidos como posições dialógicas iniciais em que os atores se encontram antes de se engajarem em um processo de deliberação e formação de consensos." (:200, ênfases minhas)

Eisenberg afirma que o processo de formação de consensos por meio de deliberação resulta em quatro cenários nas posições iniciais, a saber: SS, SN, NS e NN (ver Quadro 1). Por exemplo, em SS, os atores chegam a um consenso em relação à justificação e aplicação das normas, ou seja, elas são consideradas justas e suas conseqüências também são aceitas, o que acarreta a adesão dos atores ao comportamento 
determinado por elas; em SN, por outro lado, há consenso quanto à justificação, pois os atores as assumem como justas, mas não aceitam os resultados destas, ou seja, eles não aderem ao que elas estipulam. Como vimos acima, Habermas afirma que, se regras de interação social são reconhecidas como legítimas pelos seus destinatários, a expectativa é que a maioria as aceite e se comporte de acordo com o que elas estipulam; os casos de não-aceitação são resolvidos pela imposição de sanções. Portanto, segundo Habermas, uma situação na qual os atores sociais consideram as normas justas, mas esses mesmos atores não aceitam os "resultados" das mesmas, ou seja, não aceitam seguir o que elas estipulam, seria algo esdrúxulo. Eisenberg, porém, não vê necessidade de justificar essa questão, tomando-a como não problemática.

Quadro 1

Justificação e Aplicação

\begin{tabular}{|l|c|c|c|c|}
\hline Justificação & S & N & N & S \\
\hline Aplicação & S & S & N & N \\
\hline Posição inicial & SS & NS & NN & SN \\
\hline
\end{tabular}

Fonte: Eisenberg (2001:200).

Além do problema conceitual - ou seja, o entendimento de "aplicação" como "aceitação" de normas -, temos outro problema no texto de Eisenberg transcrito acima, dessa vez de consistência lógica. Ele nos diz que a deliberação gera os cenários das posições iniciais, mas também que estas correspondem à situação em que se encontram os atores antes da deliberação e formação de consenso. Em outras palavras, a deliberação dá origem aos cenários das posições iniciais (SS, SN, NS e NN), mas estas também são consideradas posições anteriores à deliberação. O que podemos concluir dessa passagem do texto? Há deliberação ou não há deliberação nas posições iniciais? Se não há deliberação, as posições iniciais só podem corresponder a decisões tomadas individualmente pelos atores: cada indivíduo escolhe, de acordo com a sua razão monológica, como se colocará em relação às normas. Mesmo considerando o alto grau de abstração e simplificação inerente a qualquer modelo teórico, a possibilidade de ocorrer convergência de posições em uma comunidade política por meio de uma deliberação monológica é implausível. Um simples "experimento de pensamento" indica essa limitação: imagine centenas ou milhares de indivíduos escolhendo uma das posições iniciais possíveis. A possibilidade 
de a comunidade política como um todo vir a assumir uma dessas posições sobre um conjunto de normas é mais do que remota ${ }^{6}$. Nesse sentido, se considerarmos que as posições iniciais são escolhas individuais, sem deliberação coletiva, o modelo dos consensos democráticos só permite um único resultado plausível: uma comunidade política onde há total divergência nos planos da justificação e aplicação, o que, segundo Eisenberg, resulta no "consenso autoritativo", ou seja, no modelo hobbesiano.

Mesmo considerando que há deliberação coletiva nas posições iniciais, o problema da convergência não desaparece. Eisenberg dá a entender que elas correspondem a um momento no qual todas as regras de interação social são deliberadas uno actu, pois argumenta que só existem quatro possibilidades quanto ao resultado da deliberação. Portanto, ou há consenso na justificação e aplicação de todas as normas (SS), ou há consenso na justificação de todas as normas, mas não há consenso na aplicação de todas as normas (SN), e assim por diante. O cenário mais plausível seria que cada regra de interação social fosse submetida a uma deliberação independente e, dessa forma, cada uma poderia assumir uma das quatro posições possíveis. Ao final, também não haveria uma convergência de todas as normas para apenas um cenário. Com isso, teríamos uma pluralidade de cenários que, segundo o modelo, resultaria, uma vez mais, no "consenso autoritativo". Mas não é só a convergência de posições que se mostra implausível. A própria existência de "normas" nas posições iniciais é problemática, pois o modelo dos consensos democráticos pressupõe que elas seriam externas à comunidade política, pois são consideradas $d a$ dos do contexto e os atores sociais limitam-se a avaliá-las nos planos da justificação e aplicação. Como nada sabemos sobre a origem das mesmas, só podemos concluir que são elaboradas por um "soberano". Portanto, o modelo dos consensos democráticos, segundo suas próprias premissas, se vê limitado ao modelo hobbesiano. Para que possamos prosseguir na discussão do modelo dos consensos democráticos, passo a assumir suas premissas sem levar em conta as limitações que acabei de mencionar. Portanto, na discussão que se segue, considero que há deliberação nas posições iniciais e que as normas (externas à comunidade política) são deliberadas uno actu.

Vejamos agora como interpretar o modelo. Eisenberg parece se referir a dois momentos distintos de deliberação: o primeiro corresponde ao processo decisório na posição inicial e o segundo à escolha do meca- 
nismo de arbitragem. Entretanto, essas não são duas decisões independentes, pois o resultado da deliberação nas posições iniciais (SS, $\mathrm{SN}, \mathrm{NS}$ e NN) determina qual será o mecanismo de arbitragem escolhido. Vejamos mais atentamente as características dos pares, representando os cenários das posições iniciais: em SS, os atores concordam com a validade e com a aplicação das normas (há consenso); em SN, os atores aceitam as normas como válidas, mas não a aplicação das mesmas sob o contexto considerado (não há consenso); em NS, os atores não concordam com a validade das normas, mas estão de acordo com a aplicação destas (o que resulta em um paradoxo conceitual, já que o discurso de justificação precede o discurso de aplicação); em NN, os atores não concordam nem com a validade nem com a aplicação das normas (não há consenso, mas também não haveria necessidade do discurso de aplicação). Utilizando-nos dos conceitos da ética do discurso de Habermas, as posições iniciais resultam em quatro cenários: um consenso, um paradoxo conceitual e dois dissensos. No entanto, o modelo considera que esses cenários não consensuais não afetam a legitimidade dos mecanismos de arbitragem. Como explicar, então, a relação entre as posições iniciais e os mecanismos de arbitragem? Deixaremos esta questão em suspenso por um momento.

Para Habermas (1990:122), o discurso prático não envolve nenhum conteúdo normativo substantivo: "Qualquer conteúdo, não importa quão fundamentais sejam as normas de ação, deve ser submetido a um discurso real [...]". O princípio de universalização e o princípio de propriedade também não possuem nenhum conteúdo normativo substantivo, pois o primeiro corresponde a critérios que os participantes do discurso utilizam ao deliberarem sobre normas morais, e o segundo ao processo de hierarquização de normas morais. No modelo dos consensos democráticos, porém, conteúdos normativos substantivos são introduzidos na forma de "princípios de justificação" e "princípios de aplicação" (ver Quadro 2), sendo que o conteúdo do primeiro determina o do segundo. Segue o argumento apresentado por Eisenberg:

"A cada princípio de justificação corresponde um princípio que articula no plano da eficácia das normas, isto é, no plano da propriedade da sua aplicação, uma estratégia de ação coletiva para os atores. Os princípios de aplicação, portanto, traduzem princípios de justificação em questões de ordem prática que podem ser institucionalizados. Os mecanismos de arbitragem, por sua vez, constituem os instrumentos 
específicos através dos quais o subsistema político gera a eficácia das normas. O subsistema político opera por intermédio de mecanismos de arbitragem cuja função é precisamente reproduzir e revigorar consensos inicialmente produzidos pelos atores sem ter que recorrer permanentemente a instrumentos de deliberação." (:203)

Os princípios de justificação são os mais importantes para o modelo dos consensos democráticos, pois é a partir deles que cada um dos "consensos democráticos" é definido. Retomando a pergunta feita acima, os argumentos apresentados por Eisenberg para cada um dos consensos democráticos fornecem a resposta sobre a relação entre as posições iniciais e os mecanismos de arbitragem. Vejamos o argumento referente à origem do "consenso comunitarista":

"Na medida em que os atores compartilham de uma mesma concepção moral do bem comum, o mecanismo de arbitragem primordial será a reafirmação da tradição que é comum aos atores, institucionalizada na forma de costumes cuja legitimidade deriva da identificação dos membros com os valores sancionados simbolicamente pela cultura." (ibidem)

Em outras palavras, uma concepção ético-política do "bom" compartilhada pelos membros da comunidade política resultaria no princípio de justificação "identidade" que emerge do consenso sobre as normas de interação social (cenário SS). Com isso, a comunidade política adota um princípio de aplicação "reprodução de valores" e tem preferência por um mecanismo de arbitragem que corresponda à "reafirmação da tradição". Já que há consenso sobre as normas presentes na comunidade, tudo o que os atores políticos desejam é reproduzir essa condição. Vamos examinar agora o argumento apresentado para as conseqüências do cenário inicial $\mathrm{SN}$, que resulta no "consenso republicano":

“No caso [...], em que há uma concordância no plano da justificação, sem uma compreensão comum de como aplicar as normas convergentes, caímos em um cenário que pode ser explicado nos termos do discurso republicanista. A existência de uma convergência somente no plano da justificação remete ao conceito republicanista de fundação, segundo o qual toda comunidade política, para se sustentar, depende de um momento original em que consensualmente se delimita a cidadania. Nesse contexto, a aplicação das normas dá-se via a afirmação de virtudes cívicas." (:205) 
A Ética do Discurso e o Modelo dos Consensos Democráticos...

Quadro 2

Tipologia de Consensos Democráticos

\begin{tabular}{|c|c|c|c|c|c|c|}
\hline $\begin{array}{c}\text { Posição } \\
\text { Inicial }\end{array}$ & $\begin{array}{c}\text { Princípio de } \\
\text { Justificação }\end{array}$ & $\begin{array}{c}\text { Princípio de } \\
\text { Aplicação }\end{array}$ & $\begin{array}{c}\text { Tipo de } \\
\text { Consenso }\end{array}$ & $\begin{array}{c}\text { Mecanismo de } \\
\text { Arbitragem }\end{array}$ & Instituição & Sanção \\
\hline SS & identidade & $\begin{array}{c}\text { reprodução de } \\
\text { valores }\end{array}$ & comunitarista & $\begin{array}{c}\text { reafirmação } \\
\text { da tradição }\end{array}$ & costume & $\begin{array}{c}\text { simbólica } \\
\text { (cultura) }\end{array}$ \\
\hline NS & tolerância & $\begin{array}{c}\text { proteção de } \\
\text { liberdades }\end{array}$ & liberal & $\begin{array}{c}\text { distribuição } \\
\text { de direitos }\end{array}$ & lei & $\begin{array}{c}\text { jurídica } \\
\text { (direito) }\end{array}$ \\
\hline NN & segurança & $\begin{array}{c}\text { imposição de } \\
\text { obediência }\end{array}$ & autoritativo & $\begin{array}{c}\text { exercício da } \\
\text { soberania }\end{array}$ & diretivas & $\begin{array}{c}\text { coercitiva } \\
\text { (poder) }\end{array}$ \\
\hline fundação & $\begin{array}{c}\text { firmação de } \\
\text { virtudes cívicas }\end{array}$ & republicano & $\begin{array}{c}\text { distribuição } \\
\text { de deveres } \\
\text { cívicos }\end{array}$ & procedimento & $\begin{array}{c}\text { exclusão } \\
\text { (cidadania) }\end{array}$ \\
\hline
\end{tabular}

Fonte: Eisenberg (2001:206).

Se deixarmos um pouco de lado a descrição tradicional do modelo civil-republicano, concluímos que essa descrição também poderia ser aplicada ao "consenso comunitarista" (cenário SS). De fato, o parentesco entre as abordagens comunitarista e civil-republicana é conhecido, tendo sido discutido por Habermas (1998a). Os consensos "comunitarista" e "republicano" seriam o resultado tanto do cenário inicial SS como do cenário inicial SN. O fato de no "consenso comunitarista" haver convergência no plano da aplicação e no "consenso republicano" não haver não parece ser relevante para a argumentação. Exceto pelas expressões comumente usadas na literatura de teoria política, não há diferença entre os contextos dos "consensos comunitarista e republicano": em ambos os atores políticos compartilham uma mesma concepção de bem comum, que se expressa na convergência no plano da justificação. Raciocínio análogo pode ser aplicado em relação aos "consensos liberal e autoritativo". Examinemos os argumentos apresentados por Eisenberg sobre o "consenso liberal":

“Quando há discordância no primeiro destes planos [ou seja, o plano da justificação], ainda que haja concordância no segundo [isto é, o plano da aplicação], os atores precisam apoiar-se em um princípio comum de justificação baseado na tolerância à diversidade moral, e buscar, conseqüentemente, um princípio de aplicação baseado na proteção de liberdades individuais. O mecanismo de arbitragem corres- 
pondente é a distribuição de direitos, institucionalizados na forma de leis sancionadas juridicamente pelo subsistema do direito." (:204)

Segundo esse argumento, na posição inicial NS, os atores sociais não têm uma concepção compartilhada do "bom" e, por isso, acham que é desejável um mecanismo de arbitragem baseado na garantia da liberdade individual. Tal argumento parece bastante razoável: como há conflito entre as concepções éticas, os atores políticos sentem necessidade de regular suas ações por meio do mecanismo de arbitragem "distribuição de direitos". Porém, qual seria o papel da convergência no plano da aplicação? Eisenberg não fornece uma resposta a esta pergunta. O argumento que justifica a origem do "consenso autoritativo", resultante do cenário da posição inicial NN, também não esclarece essa questão. Ei-lo:

“Mas o que acontece quando há discordância em ambos os planos? É
possível um consenso entre atores que divergem tanto nas normas de
justificação quanto nas de aplicação? Este é o cenário mais difícil de
intuir, já que aparentemente não há consenso algum se há divergência
em ambos os planos. Mas, desde que os atores continuem buscando a
reprodução do corpo político ao qual pertencem, existe um princípio
de justificação que opera mesmo quando não há convergência na jus-
tificação e aplicação de normas. Esse princípio pode ser traduzido em
termos de segurança e é melhor ilustrado pelo modelo hobbesiano." $(: 205)$

Se os atores no cenário NN não compartilham das mesmas concepções do "bom", não poderiam ter optado pelo "consenso republicano"? Para Habermas (1998a), é isso que indica uma inconsistência fundamental do modelo hobbesiano, pois ele está baseado no pressuposto de que os atores não aceitam as regras que poderiam auto-impor-se, mas estariam dispostos a aceitar as normas impostas por um soberano. Por isso, Habermas (idem:90) afirma que Hobbes pode ser lido mais "como um teórico do estado de direito burguês sem democracia do que como um apologista do absolutismo ilimitado". Habermas observa que Hobbes não consegue justificar a decisão de delegar ao soberano a imposição de todas as normas de interação social a partir da perspectiva de atores auto-interessados. $O$ consenso subjacente à idéia de contrato introduz o pressuposto de que os atores no estado da natureza já tenham capacidade de se reconhecerem mutuamente como portadores de direitos e de agirem por meio da concep- 
ção do "nós" social. No modelo dos consensos democráticos, a concepção de um "nós" também tem que ser pressuposta como "consenso autoritativo" e está expressa no argumento da busca da "reprodução do corpo político". Tal como o modelo hobbesiano, o "consenso autoritativo" não consegue justificar por que atores políticos preferem um soberano que impõe normas de cima para baixo à alternativa de escolherem, eles mesmos, as normas de interação social.

No que se refere à questão da legitimidade, os conceitos de "aplicação" e "justificação" incorporados aos cenários das posições iniciais também são um problema para o modelo dos consensos democráticos. Não irei tratar aqui os argumentos que Eisenberg apresenta para cada um dos "consensos democráticos". É suficiente lembrar a sugestão de que, ao se romper um consenso, há a possibilidade de transição para um outro tipo; caso isto não ocorra, emergem patologias sociopolíticas: apatia, fundamentalismo, separatismo e violência. No entanto, isso não é suficiente para explicar por que surgem as crises de legitimidade. Tudo o que se pode aferir do modelo dos consensos democráticos é que as crises podem ocorrer. A transição sem crises para outros consensos é explicada pelas alterações nas posições iniciais, mas o modelo não fornece uma razão para o rompimento dos consensos em torno dos mecanismos de arbitragem. Tudo o que Eisenberg nos diz é que

"[...] em todo e qualquer momento desse processo, existe a real possibilidade de que o subsistema político não consiga produzir o consentimento dos atores. Dependendo do consenso que define a posição dos agentes naquele momento, determinados tipos de crise de legitimidade política podem surgir, e a natureza dessas crises é determinada precisamente pelo tipo de consenso que é rompido naquele momento." (:209)

Esse argumento não é uma explicação para a eclosão de crises de legitimidade, mas restringe-se a uma hipótese de que as crises, quando ocorrem, assumem características que são intrínsecas aos arranjos políticos que as originaram. Mas, ainda assim, falta plausibilidade ao modelo. Crises políticas geralmente apresentam todos os quatro sintomas de patologias sociopolíticas, independentemente do arranjo político que as precederam. Como se sabe, Habermas (1987) desenvolveu uma tese sobre a eclosão de patologias sociais que leva em consideração a emergência de vários sintomas simultaneamente. 
Ainda que a teoria habermasiana esteja sujeita à crítica de estar limitada ao contexto das sociedades de Bem-Estar Social, negligenciando as condições a que estão submetidos os países do Terceiro Mundo (Said, 1994), não deixa de ser uma tese consistente. A questão teórica relevante, nesse caso, me parece ser menos qual arranjo político origina que sintoma, e sim se a explicação habermasiana para as crises do capitalismo tardio pode ser relevante para o contexto dos países subdesenvolvidos. Mas, por ora, vamos deixar esta questão de lado, retornando à discussão do modelo dos consensos democráticos.

Ao que parece, a incompatibilidade entre a abordagem habermasiana e o modelo dos consensos democráticos reside também na inspiração contratualista do último. A idéia de posições iniciais requer - como acontece nos casos do "estado da natureza" de Hobbes e do "véu de ignorância" de Rawls - a postulação de "situações objetivas", ou seja, requer que sejam atribuídos conteúdos substantivos aos valores, normas e interpretações dos atores na posição inicial. Como mostrei acima, é justamente isso que Habermas deseja evitar com a ética do discurso, que parte apenas dos pressupostos de que normas morais são validadas intersubjetivamente e que os atores envolvidos consideram ser possível atender ao princípio (U). Desse argumento vem a crítica que Habermas dirige a Rawls:

\footnotetext{
“Rawls impõe uma perspectiva comum às partes na posição original por meio de restrições nas informações disponíveis e, assim, neutraliza a multiplicidade de perspectivas de interpretação particulares desde o início. A ética do discurso, em contraste, vê o ponto de vista moral como incorporado a uma práxis de argumentação intersubjetiva que leva aqueles envolvidos a um alargamento idealizado de suas perspectivas interpretativas." (Habermas, 1998b:57)
}

Portanto, diferentemente do que Eisenberg considera, a ética do discurso de Habermas não está limitada a "um único horizonte normativo [...] através do qual derivamos certos pré-requisitos ou princípios primeiros para uma concepção de justiça" (:210). A idéia do princípio (U) tem justamente o objetivo de submeter qualquer conteúdo normativo de condutas morais ao processo de argumentação. O modelo dos consensos democráticos, por outro lado, está fundamentado em conteúdos normativos substantivos, apresentados na forma de princípios de justificação. 
A Ética do Discurso e o Modelo dos Consensos Democráticos...

\section{CONSIDERAÇÕES FINAIS}

O modelo dos consensos democráticos apresenta problemas tanto de consistência teórica como de coerência conceitual. Como vimos, os próprios pressupostos do modelo dificilmente podem ser considerados plausíveis. Parece, entretanto, que o ponto crítico do modelo dos consensos democráticos reside no mal-entendido que afetou os conceitos da ética do discurso de Habermas. "A plicação" não é aceitação (ou rejeição) de normas, como supõe Eisenberg, mas um passo adicional ao processo discursivo sobre normas morais. Portanto, os conceitos de discurso de justificação e discurso de aplicação não são o recurso conceitual mais adequado para interpretar o que ocorre nas posições iniciais. Ao adotar-se os argumentos da ética do discurso de Habermas para interpretar os cenários das posições iniciais, só se pode concluir que os três cenários não consensuais são apenas um momento de instabilidade normativa inerente ao processo de deliberação discursiva ${ }^{7}$. Embora Habermas apresente vários tipos de "princípios" - princípio de discurso, princípio de universalização, princípio de propriedade e princípio de democracia -, estes não apresentam nenhum vínculo com os princípios de justificação e os princípios de aplicação introduzidos por Eisenberg. Estes últimos parecem derivar das características dos modelos tradicionais de arranjos políticos: comunitarismo, liberalismo, civil-republicanismo e contrato social hobbesiano. Essa impressão é quase inevitável, uma vez que o modelo dos consensos democráticos não conseguiu demonstrar a relevância da deliberação no plano da aplicação para a gênese dos quatro "consensos democráticos". Por esse motivo, o modelo dos consensos democráticos parece ter sido construído "de trás para a frente": primeiro teriam sido escolhidos os quatro tipos de arranjos políticos e a partir deles chegou-se aos princípios de justificação e aos demais componentes do modelo. Os cenários resultantes da deliberação nas posições iniciais tornam-se o último elo do argumento e não o primeiro, como parece ter sido a intenção de Eisenberg.

Quanto aos princípios de justificação introduzidos no modelo dos consensos democráticos, partindo-se da ética do discurso de Habermas, eles só podem ser compreendidos como argumentos que atores em situações concretas poderiam apresentar no momento de deliberação sobre o mecanismo de arbitragem. Nesse caso, a concepção das posições iniciais deixa de ter pertinência, pois o que é relevan- 
te é o discurso prático sobre os mecanismos de arbitragem. Como os conceitos da ética do discurso de Habermas não se referem a conteúdos normativos substantivos, mas apenas aos princípios que regem os discursos práticos, parece-me que a abordagem da teoria moral de Habermas foi de pouca utilidade para o modelo dos consensos democráticos.

Quanto aos quatro tipos de arranjos políticos que servem para fundamentar o modelo dos consensos democráticos, poderíamos nos perguntar se são mesmo quatro ou se se limitam a dois. Se aceitarmos o argumento de que o modelo hobbesiano é inconsistente, como sustenta Habermas, ou, simplesmente, que não é democrático, e também que o modelo comunitarista é uma versão contemporânea do modelo civil-republicano, então estariam em jogo apenas dois tipos de arranjos políticos relevantes: o "consenso liberal" e o "consenso republicano". São justamente esses dois modelos de democracia que Habermas busca integrar ao longo da argumentação que ele desenvolve em Between Facts and Norms (1998a). Dessa maneira, aquilo que o seu modelo de democracia deliberativa procurou reconciliar e integrar, o modelo dos consensos democráticos buscou diferenciar e separar.

Considero que existem elementos no modelo dos consensos democráticos que, se adequadamente desenvolvidos, podem representar uma interessante contribuição para a teoria democrática. Infelizmente, não é possível comentá-los aqui. Resta-me apenas sugerir um ponto de partida para uma possível reformulação do modelo dos consensos democráticos. Estou me referindo à tentativa de Habermas (idem:371) para realizar uma tradução "do conceito de política deliberativa em termos sociológicos", pois há aqui um ponto de convergência com o objetivo mais amplo de Eisenberg, a saber: o desenvolvimento de uma "teoria sociológica da legitimação de normas em uma democracia" (:211). Naturalmente, essa sugestão dependerá de o autor continuar a reconhecer na teoria habermasiana uma referência adequada aos seus objetivos.

(Recebido para publicação em outubro de 2002) 


\section{A Ética do Discurso e o Modelo dos Consensos Democráticos...}

\section{NOTAS}

1. Todas as referências a Eisenberg no presente texto se referem ao artigo citado.

2. Esse é um dos aspectos mais controversos do discurso ético de Habermas. Sobre essa questão, ver Benhabib e Dallmayr (1990), Murphy III (1994) e Cohen (1994).

3. Não é possível, infelizmente, estender essa argumentação aqui, mas remeto o leitor à excelente discussão apresentada por Rehg (1997:184-210).

4. Sobre esse mal-entendido recorrente, Habermas (1986:171) comentou: "Nada me deixa mais nervoso do que a imputação de que em virtude de a ação comunicativa focar sua atenção na facticidade social das reivindicações de validade, ela propõe, ou ainda sugere, uma sociedade racionalista utópica. Eu não considero a sociedade totalmente transparente - e deixe-me acrescentar a esse contexto: ou uma sociedade homogeneizada e unificada - como um ideal, nem desejo sugerir nenhum outro ideal - Marx não foi o único a se assustar com os vestígios de um socialismo utópi$\mathrm{CO}^{\prime \prime}$.

5. Eisenberg utiliza a palavra "propriedade" como tradução do termo alemão Angemessenheit. Decidi manter esta tradução neste artigo, embora uma mais fiel ao sentido de principle of appropriateness, utilizado na tradução em inglês (Habermas, 1993), seja "princípio do apropriado".

6. O "experimento de pensamento" pode ser estruturado nos seguintes termos: uma vez que a posição inicial NN corresponde a um total dissenso, precisamos saber apenas qual é a probabilidade de convergência nas três posições iniciais restantes SS, SN e NS, tendo como pressuposto que as três são igualmente possíveis. Em uma comunidade política qualquer, composta por $n$ pessoas e $m$ normas, essa probabilidade é expressa pela fórmula $3 / 3^{\wedge}(m \times n)$. Portanto, para uma comunidade composta por dez pessoas e duas normas, a probabilidade de convergência em qualquer uma das três posições iniciais é de apenas 0,0000001\%.

7. É por isso que Habermas (1998a) considera que em sociedades complexas é preciso institucionalizar o sistema legal, pois de outro modo a instabilidade normativa dos processos comunicativos inviabilizaria a integração social. Por outro lado, Habermas considera que essa instabilidade comunicativa é fundamental para garantir a dinâmica da formação da opinião e vontade políticas na esfera pública. 


\section{Christina W. Andrews}

\section{REFERÊNCIAS BIBLIOGRÁFICAS}

BENHABIB, Seyla e DALLMAYR, Frederick. (1990), The Communicative Ethics Controversy. Cambridge, MIT Press.

COHEN, Jean. (1994), “Jean Cohen Responds”. New German Critique, no62, pp. 137-148.

EISENBERG, José. (2001), “Justificação, Aplicação e Consenso: Notas sobre Democracia e Deliberação". Dados, vol. 44, no 1, pp. 195-213.

HABERMAS, Jürgen. (1971), Knowledge and Human Interest (traduzido por J. J. Shapiro). Boston, Beacon Press.

. (1984), The Theory of Communicative Action: Reason and the Rationalization of Society (traduzido por Thomas McCarthy). Boston, Beacon Press, vol. 1.

. (1986), “A Philosophical-Political Profile: Written Interview with Perry Anderson and Peter Dews", in P. Dews (ed.), Autonomy and Solidarity: Interviews with Jürgen Habermas. London, Verso, pp. 147-185.

(1987), The Theory of Communicative Action: Lifeworld and System - A Critique of Functionalist Reason (traduzido por Thomas McCarthy). Boston, Beacon Press, vol. 2.

. (1990), Moral Consciousness and Communicative Action. Cambridge, MIT Press.

. (1993), Justification and Application: Remarks on Discourse Ethics. Cambridge, MIT Press.

. (1998a), Between Facts and Norms: Contributions to a Discourse Theory of Law and Democracy (traduzido por William Rehg). Cambridge, MIT Press.

. (1998b), "Reconciliation through the Public Use of Reason", in C. Cronin e P. De Greiff (eds.), The Inclusion of the Other: Studies in Political Theory. Cambridge, MIT Press, pp. 49-73.

JAY, Martin. (1984), Marxism and Totality: The Adventures of a Concept from Lukács to Habermas. Cambridge, Polity.

LEIVESLEY, R., CARR, A. e KOUZMIN, A. (1994), “Max Weber: Victim of Ethnocentric Mishandling or How Weber Became a Management Consultant", in A. Farazmand (ed.), Handbook of Bureaucracy. New York, Marcel Dekker, pp. 41-64.

MCCARTHY, Thomas. (1981), The Critical Theory of Jürgen Habermas. Cambridge, MIT Press.

MURPHY III, Thomas F. (1994), "Discourse Ethics: Moral Theory or Political Ethic?". New German Critique, no 62, pp. 111-133.

REHG, William. (1997), Insight \& Solidarity: The Discourse Ethics of Jürgen Habermas. Berkeley, University of California Press.

SAID, Edward W. (1994), Culture and Imperialism. New York, Vintage Books. 
A Ética do Discurso e o Modelo dos Consensos Democráticos...

\begin{abstract}
Discourse Ethics and the Model of Democratic Consensus: A Reply to J. Eisenberg
\end{abstract}

The present article is a critical analysis of the model proposed by José Eisenberg in "Justificação, Aplicação e Consenso: Notas sobre Democracia e Deliberação" (Dados, 44(1):195-213, 2001), which aims to explain the genesis of political arrangements in contemporary democracies. The article's analysis focuses on Jürgen Habermas' "discourse ethics" concepts, adopted by the model in question as its main theoretical reference. Based on the works of the German philosopher and social theorist, the article seeks to demonstrate that these concepts were initially developed from the Habermasian notion of discourse and, consequently, are not based on empirical consensus, as the model under analysis suggests. The article also points to other problems in the model's theoretical consistency and suggests an approach for its improvement.

Key words: democratic theory; deliberative democracy; discourse ethics

\title{
RÉSUMÉ
}

Éthique du Discours et le Modèle du Consensus en Démocratie: Une Réplique à J. Eisenberg

Dans cet article, on fait une analyse critique du modèle proposé par José Eisenberg dans son texte "Justificação, Aplicação e Consenso: Notas sobre Democracia e Deliberação" (Dados, 44(1):195-213, 2001), où il cherche à expliquer la genèse des arrangements politiques dans les démocraties contemporaines. Dans le présent article, on examine l'idée d'"éthique du discours" selon Habermas, que le modèle en question choisit pour référence théorique principale. En se basant sur l'oeuvre du philosophe et théoricien social allemand, dont on cherche à montrer que les idées ont été bâties sur sa conception du discours et ne reposent donc pas sur le consensus empirique, tel que le modèle analysé le suggère. On y décèle aussi d'autres faiblesses quant à la théorie présentée dans ce modèle auquel des modes d'amélioration sont proposés.

Mots-clé: théorie démocratique; démocratie délibérative; éthique du discours 